\title{
Boruların Çift Geçişli Paralel Tüp Kanal Açısal Presleme (DP- PTCAP) Yöntemi ile Aşırı Plastik Deformasyon Analizi
}

\author{
Vedat TAŞDEMIR* \\ Makine ve Metal Teknolojileri Bölümü, Elbistan Meslek Yüksekokulu, Kahramanmaraş İstiklal Üniversitesi, \\ Kahramanmaraş, Türkiye \\ vedat.tasdemir@istiklal.edu.tr
}

(Geliș/Received: 11/11/2019;

Kabul/Accepted: 04/07/2020)

\begin{abstract}
Öz: Așırı plastik deformasyon (APD), nano yapılı ve ultra ince taneli malzemeler elde edilmesi amacı ile kullanılan bir yöntemdir. Tüp şeklindeki malzemelerin aşırı plastik deformasyonunda kullanılan birçok yöntem vardır. Bu yöntemlerden biri de paralel tüp kanal açısal presleme (PTCAP) yöntemidir. Bu çalışmada, boru şeklindeki parçaların deformasyonu çift geçişli paralel tüp kanal açısal presleme (DP-PTCAP) metodu kullanılarak araştırılmıştır. Analizlerde, 5 farklı kanal açısı, 4 farklı kesit genişleme oranı ve 4 farklı boyutsuz uzunluk kullanılmıştır. Bu parametrelerin elde edilen tüp (boru) şeklindeki parçaların gerilme, birim şekil değișimi ve şekillendirme kuvvetine etkileri sonlu elemanlar yöntemi ile analiz edilmiștir. Çalışmada AA6061 malzeme kullanılmıştır. Analizler sonucunda, kanal açısının artması ile efektif birim şekil değişimi, şekillendirme kuvveti ve malzemede oluşan gerilmenin azaldığı görülmüștür. Çift geçişli kalıplarla elde edilen malzemelerin birim şekil değişiminin tek geçişli kalıplara nazaran daha yüksek olduğu belirlenmiştir. Yapılan çalışma sonucu analizlerden elde edilen birim şekil değişimine bakarak çift geçişli kalıplar ile elde edilen malzemelerin tane yapısının tek geçişli kalıplara nazaran daha ince taneli olduğu söylenebilir.
\end{abstract}

Anahtar kelimeler: Aşırı plastik deformasyon, paralel tüp kanal açısal presleme, çift geçiş, sonlu elemanlar analizi, PTCAP

\section{Severe Plastic Deformation Analysis of Tubular Parts via Double Pass Parallel Tubular Channel Angular Pressing (DP-PTCAP) Method}

\begin{abstract}
Severe plastic deformation (SPD) is a method used to obtain nano-structured and ultra-fine-grained materials. There are many methods used for severe plastic deformation of tubular materials. One of these methods is parallel tubular channel angular pressing (PTCAP). In this study, deformation of tubular parts was investigated by using double pass parallel tubular channel angular pressing (DP-PTCAP) method. In the analysis, 5 different channel angles, 4 different cross section expansion rates and 4 different dimensionless lengths were used. The effects of these parameters on the stress, plastic strain and forming force of the tubular parts obtained were analyzed by finite element method. AA6061 material was used in the study. As a result of the analysis, effective strain, forming force and stress in material were decreased with increasing channel angle. It was determined that the plastic strain of the materials obtained with double pass dies was higher than single pass dies. As a result, it can be said that the grain structure of the materials obtained with double pass dies is finer grained than single pass dies.
\end{abstract}

Key words: Severe plastic deformation, parallel tubular channel angular pressing, double pass, finite element analysis, PTCAP

\section{Giriş}

Așırı plastik deformasyon (APD), malzemelerin çok büyük plastik deformasyona uğramasından dolayı ultra ince taneli ve nano yapılı metal şekillendirme yöntemi olarak tanımlanabilir [1-3]. Aşırı plastik deformasyon, malzemenin mukavemetinde artış sağlayacak şekilde malzeme tane boyutunu nano (100 nm'den daha küçük) ve ultra ince taneye $(100 \mathrm{~nm}-1 \mu \mathrm{m})$ düşürmektedir. Şekil 1'de APD esnasında mikroyapıdaki değişimlerin şematik görüntüsü verilmiştir. APD teknikleri ile ultra ince taneli malzemeler elde edilebildiği için bu durum elde edilen malzemelerin çok düşük sıcaklıklarda yüksek deformasyon oranlarına sahip süper plastik bir davranış sergilemesine yol açmaktadır [3-6]. Aşırı plastik deformasyon işleminde temel amaç, çevreyle uyumlu yüksek mukavemetli ve hafif malzemeler üretmektir. Dövme, haddeleme, ekstrüzyon gibi geleneksel metal şekillendirme işlemlerinde malzemenin maruz kaldığ 1 plastik şekil değişimi genellikle 2 'den çok daha düşüktür. Daha yüksek plastik şekil değişimine ulaşmak için uygulanan çok adımlı (geçişli) haddeleme, çekme, ekstrüzyon vb. ile üretilen malzemelerde ise kalınlık ve çapta çok fazla incelme oluştuğundan elde edilen malzemeleri kullanmak uygun değildir. Çok büyük şekil değişimine maruz bırakıldığında parça şeklinde hatalar olmadan,

*Sorumlu yazar: vedat.tasdemir@istiklal.edu.tr. Yazarın ORCID Numarası: 0000-0002-2375-9525 
homojen yapılı malzemeler üretmek için birçok APD yöntemi geliştirilmiș ve geliştirilmeye devam etmektedir $[1,2]$. APD yöntemi ile üretilen ultra ince taneli malzemeler üstün mekanik özelliklere sahiptir. Günümüzde çok farklı ve yeni APD teknikleri üzerine birçok çalışma yapılmaktadır. Bunlar içerisinde en popüler olanları; ECAP (Eş kanallı açısal presleme) [7, 8], HPT (Yüksek basınç burulması) [9], ARB (Biriktirmeli hadde yapıştırması) [10]. Boruların APD işleminde kullanılan teknikler ise şunlardır; TCP (Tüp kanal presleme), TCAP (Tüp kanal açısal presleme) [11], HPTT (Yüksek basınçlı boru burma) [12], PTCAP (Paralel tüp kanal açısal presleme) [13], t-HPS (Tüp yüksek basınçlı kesme) [14], RTES (Tekrarlayan tüp genişleme ve daralma) [15], TCEC (Tüp tekrarlı ektrüzyon-basma) [16], TCEE (Tüp tekrarlı ektrüzyon-genişleme) [17], ASB (Biriktirmeli çevirme yapışırma) [18].

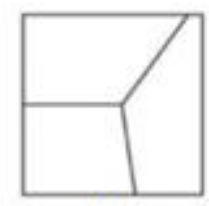

(a)

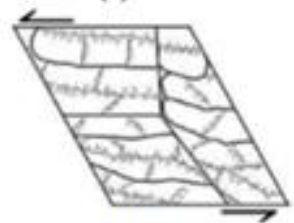

(d)

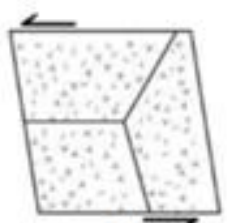

(b)

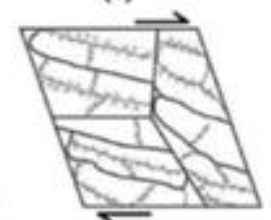

(e)

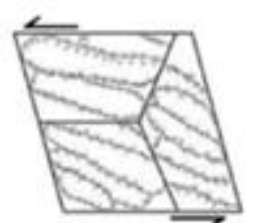

(c)

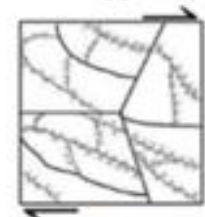

(f)

Şekil 1. Aşırı plastik deformasyonda tek geçiş esnasında ileri kayma(a-d) ve kayma şekil değişimini tersine çevirmesini(e-f) içeren mikroyapı değişiminin şematik gösterimi [19].

Faraji ve ark. [20], PTCAP yöntemini kullanarak bakır boruların dislokasyon yoğunluğunun belirlenmesi üzerine bir çalışma yapmışlardır. Çalışmalarını $120^{\circ}$ sabit kanal açısında gerçekleştirmişlerdir. Dislokasyon yoğunluğunun birinci geçişten sonra $18.1 \times 10^{9} \mathrm{~cm}^{-2}$ ye dördüncü geçişten sonra ise $2.48 \times 10^{9} \mathrm{~cm}^{-2}$ ye düştüğünü belirlemişlerdir. Yine elde edilen sertliğin 62 HV'den 142 HV'ye çıktığını belirtmişlerdir. Javidikia ve Hashemi [21] ise Al 5083 alaşımının paralel tüp kanal açısal presleme yöntemini kullanarak farklı deformasyon oranı, kanal açısı ve kavis açısının etkisini hem deneysel hem de analiz yöntemini kullanarak araştırmışladır. Çalışmalarının neticesinde deneysel sonuçlarla sonlu elemanlar analiz sonuçlarının iyi bir uyum içinde olduklarını belirtmişlerdir. Afrasiab ve ark. [22], Cu-Zn alaşımlı boruların mekanik ve mikroyapı özellikleri üzerine çok geçişli paralel tüp kanal açısal presleme yönteminin etkisi üzerine bir çalışma yapmışlardır. Çalışma neticesinde çekme dayanımının $\% 65$, akma dayanımının ise $\% 25$ oranında arttığını, $70 \mu \mathrm{m}$ olan ilk tane boyutunun çok önemli oranda düştüğünü ancak sünekliğin ise önemli oranda azaldığını belirtmişlerdir. Jafarlou ve ark. [23], eş kanal açısal presleme (ECAP) yöntemi ile boru şeklindeki AA6061 malzemenin aşırı plastik deformasyonu üzerine bir çalışma yapmışlardır. Çalışmalarında kanal açısı olarak $120^{\circ}$ ve köşe yuvarlatma açısını da $22^{\circ}$ sabit tutmuşlardır. Borunun içini hidrolik yağ ile doldurup her iki girişini de kapatmışlardır. Çalışmaları neticesinde tane boyutunun \%60 oranında azaldığı, buna karşın mekanik özelliklerin önemli ölçüde arttı̆ını belirtmişlerdir. Şahbaz ve ark. [24], yeni geliştirdikleri ince duvarlı açık kanal açısal presleme (TWOCAP) tekniğini kullanarak U kesitli AZ31 magnezyum alaşımının plastik deformasyonu üzerine bir çalışma yapmışlardır. Çalışmalarının neticesinde büyük plastik deformasyondan dolayı mikroyapı ve tane incelmesindeki değişimlere bağlı olarak tokluk, sertlik ve mukavemette iyileşmenin gözlendiğini belirtmişlerdir. Yine Şahbaz ve ark. [25], yaptıkları başka bir çalışmada TWO-CAP yönteminin AA 5083 malzemenin mekanik özelliklerine etkisini araştırmışlardır. Çalışmalarının sonucunda geçiş sayısı arttıkça sertlik ve mukavemetin arttığını ve tane yapısının ise daha da inceldiğini belirtmişlerdir.

Bu çalışmanın amacı, çift geçişli paralel tüp kanal açısal presleme yöntemini kullanarak kanal açısı, kesit genişleme oranı ve boyutsuz uzunluk parametrelerinin tüp (boru) şeklindeki parçaların gerilme, birim şekil değişimi ve şekillendirme kuvvetine olan etkilerini sonlu elemanlar yöntemi ile araştırmaktır. Bu çalışma, mevcut paralel tüp kanal açısal presleme (PTCAP) yöntemi ile ilgili yapılan çalışmalardan hem çift geçişli bir yapıya sahip olması hem de kesit genişleme oranı ve boyutsuz uzunluk gibi farklı parametrelerin kullanılması açısından yeni ve özgün bir çalışmadır. 


\section{Paralel Tüp(Boru) Kanal Açısal Presleme (PTCAP) Yöntemi}

Paralel tüp kanal açısal presleme yöntemi, boru şeklindeki parçaların belirli oranda büyütülmüş çapa sahip kanaldan geçirilerek çok yüksek plastik şekil değişimine maruz bırakılarak yüksek mukavemetli parçalar elde edilmesi yöntemidir. Paralel tüp kanal açısal presleme işlemi Faraji ve ark. [13] tarafından 2012 y1lında geliştirilmiştir. Bu yöntem Şekil 2'de görüldüğü gibi iki yarım çevrimden oluşan bir yöntemdir. Şekil 2.a'da görüldüğü gibi boru kalıp içine yerleştirilir ve zımba ile itilerek Şekil 2.b'de görüldüğü gibi çapı genişler. Daha sonra Şekil 2.c'de görüldüğü gibi ikinci zımba ile ters yönde itilerek ilk çapına geri getirilir. Bu işlem defalarca tekrarlanarak devam ettirilir.

(a)

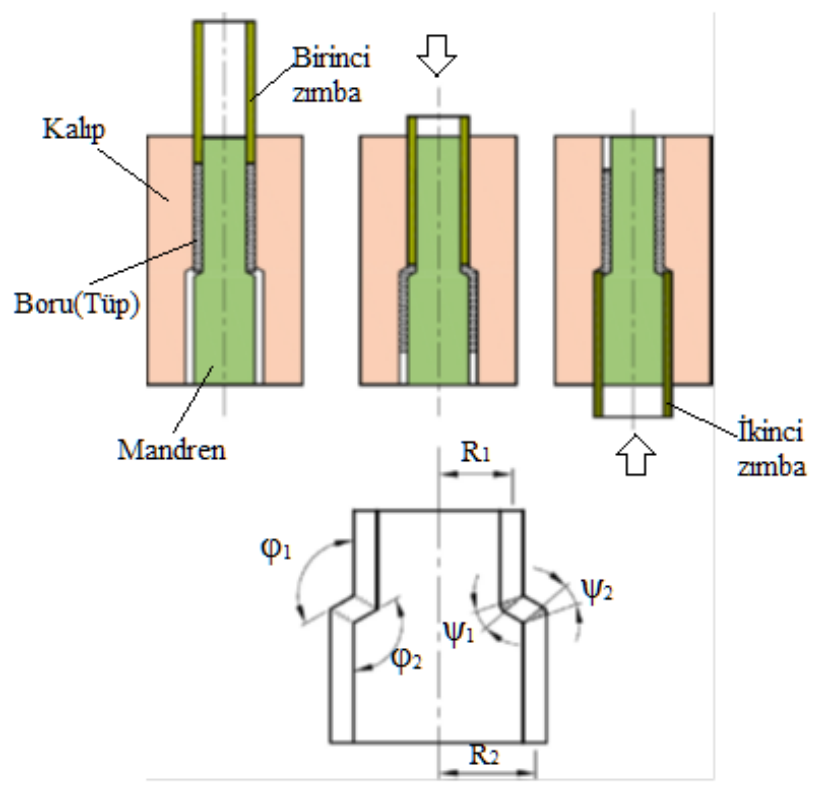

(d) (c)

Şekil 2. PTCAP işleminin şematik görüntüsü [13].

Bu yöntem kullanılarak $\mathrm{N}$ çevrim sonunda oluşan eşdeğer plastik şekil değişimi Eş. 1'de verilen formülle hesaplanmaktadır.

$\bar{\varepsilon}_{T N}=2 N\left\{\sum_{i=1}^{2}\left[\frac{2 \cot \left(\frac{\varphi_{i}}{2}+\frac{\psi_{i}}{2}\right)+\psi_{i} \operatorname{cosec}\left(\frac{\varphi_{i}}{2}+\frac{\psi_{i}}{2}\right)}{\sqrt{3}}\right]+\frac{2}{\sqrt{3}} \ln \left(\frac{R_{2}}{R_{1}}\right)\right\}$

Burada; $\varphi_{i}$ kanal geçiş açısı, $\Psi_{i}$ yuvarlatma açısı, $R_{1}$ ve $R_{2}$ sırası ile ilk ve son yarıçaptır.

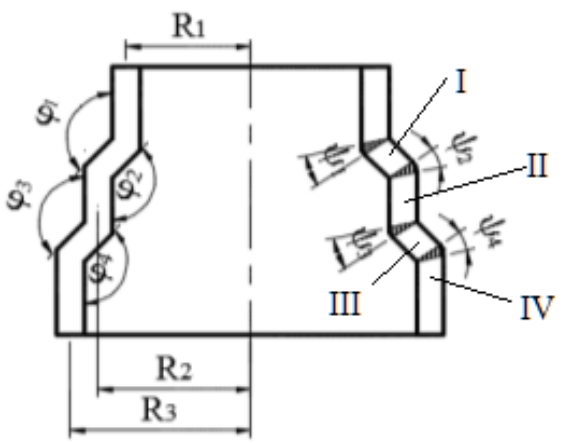

Şekil 3. Analizlerde kullanılan DP-PTCAP işlemi. 
Bu çalışmada, Şekil 3'de görülen çift kademeli (geçişli) kalıp kullanılmıştır. Bir yarım çevrim sonunda oluşan eşdeğer plastik şekil değişimi, Eş. 1 modifiye edilerek Eş. 2'de verilen formülle hesaplanabilir.

$\bar{\varepsilon}_{h}=\sum_{i=1}^{4}\left[\frac{2 \cot \left(\frac{\varphi_{i}}{2}+\frac{\psi_{i}}{2}\right)+\psi_{i} \operatorname{cosec}\left(\frac{\varphi_{i}}{2}+\frac{\psi_{i}}{2}\right)}{\sqrt{3}}\right]+\frac{2}{\sqrt{3}} \ln \left(\frac{R_{3}}{R_{1}}\right)$

$\mathrm{N}$ çevrim sonunda oluşacak toplam eşdeğer plastik şekil değişimi ise Eş. 3'te verilen formülle hesaplanabilir.

$\bar{\varepsilon}_{T}=2 N\left\{\sum_{i=1}^{4}\left[\frac{2 \cot \left(\frac{\varphi_{i}}{2}+\frac{\psi_{i}}{2}\right)+\psi_{i} \operatorname{cosec}\left(\frac{\varphi_{i}}{2}+\frac{\psi_{i}}{2}\right)}{\sqrt{3}}\right]+\frac{2}{\sqrt{3}} \ln \left(\frac{R_{3}}{R_{1}}\right)\right\}$

Burada; $\varphi_{\mathrm{i}}$ kanal geçiş açısı, $\Psi_{\mathrm{i}}$ yuvarlatma açısı, $\mathrm{R}_{1}$ ve $\mathrm{R}_{3}$ sırası ile ilk ve son yarıçaptır.

\section{Sonlu Elemanlar Analizi}

Sonlu elemanlar yöntemi, deformasyon işlemleri esnasındaki deformasyon davranışlarını daha etkili açıklamak, üretim maliyetlerini azaltmak ve optimum parametreleri belirlemek için yaygın olarak kullanılan bir yöntemdir. Çalışmada, sonlu elemanlar yazılımı olarak DEFORM-F2 programı kullanılmıştır. DEFORM-F2, Newton Raphson metodunu kullanarak çözüm yapan implisit bir nümerik koddur. Deneylerde diş çap $1 \mathrm{~d}_{\mathrm{d}}=20$ $\mathrm{mm}$, iç çap $1 \mathrm{~d}_{\mathrm{i}}=16 \mathrm{~mm}$, et kalınlığ $\mathrm{t}_{\mathrm{o}}=2 \mathrm{~mm}$ ve boyu ise $30 \mathrm{~mm}$ ölçülerinde AA6061 boru(tüp) malzeme kullanılmış ancak 28 mm'lik kısmı şekillendirilmiştir. Kullanılan malzemenin özellikleri programın malzeme kütüphanesinden alınmıştır. Analizler oda sıcaklığında ve $1 \mathrm{~mm} / \mathrm{s}$ zımba hızında gerçekleştirilmiştir. Kalıp, zımba, boru ve mandren üç boyutlu olarak tasarlanmış ancak analizler, çözüm kolaylığı sağlamak adına eksenel simetrik olarak iki boyutlu yapılmıştır. Analizlerde sürtünme katsayısı m=0.08, yuvarlatma açıları $\Psi_{\mathrm{i}}=0$ alınmıştır. Analizlerde kullanılan parametreler Tablo 1'de verilmiştir. DP-PTCAP işleminde kanal açısının $(\varphi)$ etkisi belirlenirken $R_{A} / R_{T}$ ve $L / d_{i}$ sırası ile 0.5 ve 0.25 ; kesit genişleme oranının $\left(R_{A} / R_{T}\right)$ etkisi analiz edilirken $\varphi=135^{\circ}$ ve $\mathrm{L} / \mathrm{d}_{\mathrm{i}}=0.25$; ve boyutsuz uzunluk oranının $\left(\mathrm{L} / \mathrm{d}_{\mathrm{i}}\right)$ etkisi belirlenirken de kanal aç1S1 $\varphi=135^{\circ}$ ve $\mathrm{R}_{\mathrm{A}} / \mathrm{R}_{\mathrm{T}}=0.5$ sabit alınarak analizler gerçekleştirilmiştir. Analizlerde kullanılan DP-PTCAP deney seti Şekil 4 'te verilmiştir.

Tablo 1. Analiz parametreleri.

\begin{tabular}{|c|c|c|c|c|}
\hline \multirow[t]{2}{*}{ Parametre } & \multirow[t]{2}{*}{ Seviyeler } & \multicolumn{3}{|c|}{ Diğer parametreler } \\
\hline & & $\varphi\left({ }^{\circ}\right)$ & $\mathrm{R}_{\mathrm{A}} / \mathrm{R}_{\mathrm{T}}$ & $\mathrm{L} / \mathrm{d}_{\mathrm{i}}$ \\
\hline Kanal açıSı, $\varphi\left(^{\circ}\right)$ & $165,150,135,120,105$ & - & 0.5 & 0.25 \\
\hline Kesit genişlemesi oranı, $\mathbf{R}_{\mathrm{A}} / \mathbf{R}_{\mathrm{T}}$ & $0,0.25,0.5,0.75$ & 135 & - & 0.25 \\
\hline Boyutsuz uzunluk oranı, $\mathrm{L} / \mathbf{d}_{\mathrm{i}}$ & $0,0.125,0.25,0.5$ & 135 & 0.5 & - \\
\hline $\begin{array}{l}\text { Cift geçiş için deformasyon oranları, } \\
\mathbf{K}_{1}=K_{2}\end{array}$ & $1 . t_{0}$ & - & - & - \\
\hline $\begin{array}{l}\text { Tek geçiş için deformasyon oranları, } \\
K\left(K_{1}+K_{2}\right)\end{array}$ & 2.t. $\mathrm{t}_{0}$ & - & - & - \\
\hline Kesit genişleme oranı, $\mathbf{R}_{T}$ & $2 . \mathrm{t}_{0}$ & - & - & - \\
\hline
\end{tabular}




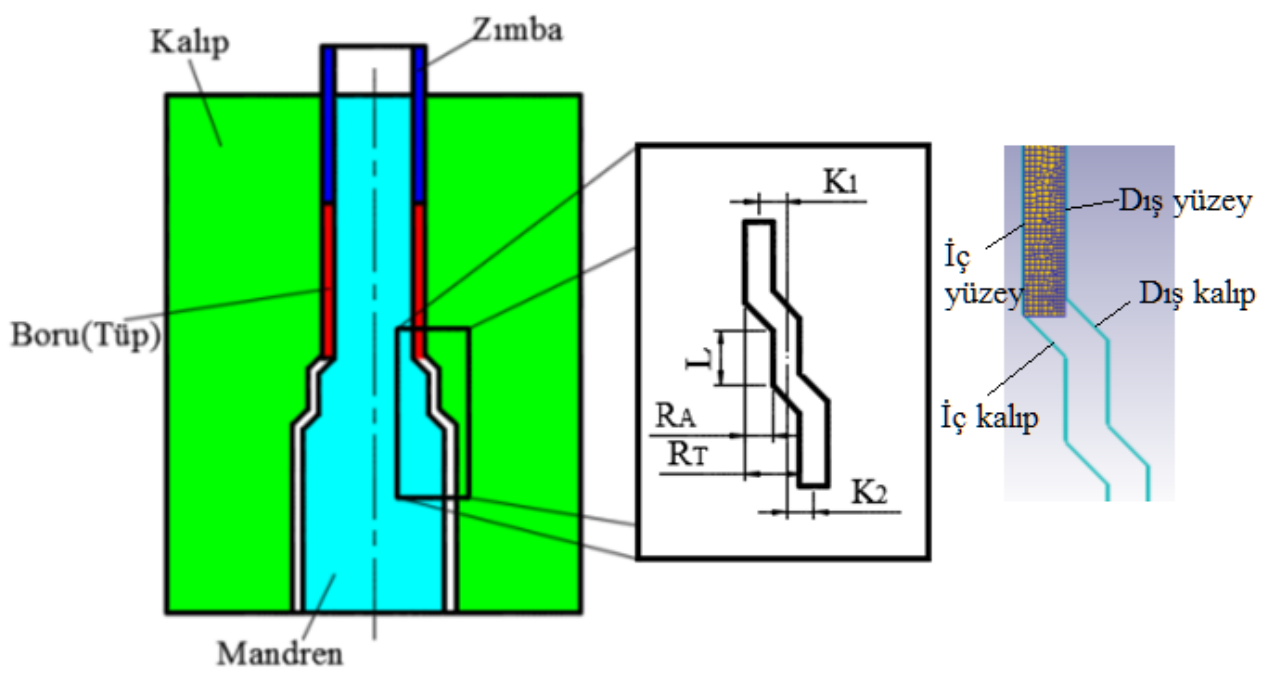

Şekil 4. Analizlerde kullanılan deney seti.

\section{Bulgular ve Tartışmalar}

\subsection{Gerilme dağılımı}

Çift geçişli kalıplar için yapılan analizler sonucu kanal açısı, kesit genişleme oranı ve boyutsuz uzunluğun parça üzerindeki gerilme dağılımına etkileri sırası ile Şekil 5, Şekil 6 ve Şekil 7'de verilmiştir. Deformasyon bölgesindeki efektif gerilme bölgelerini iyi bir şekilde analiz etmek, kayma deformasyonu ve plastik bölgeler hakkında bazı bilgilerin elde edilmesini sağlar [26]. Şekiller birlikte incelendiğinde en büyük gerilmelerin geçiş bölgelerinde (I ve III) olduğu görülmektedir. Bu bölgelerdeki yoğun süreksiz kaymalar gerilme değerlerini büyütür [11]. Kanal açısının küçülmesi ile malzeme akışı zorlaşmakta, deformasyon oranı ise artmaktadır. Bu durum ise daha yüksek gerilme oluşumuna neden olmaktadır. Başka bir ifade ile kanal açısı büyüdükçe gerilme azalmaktadır. Ancak en kötü gerilme dağılımı $\varphi=165^{\circ}$ kalıpta oluşmaktadır. Bu durum geçiş bölgesi mesafesi uzadıkça süreksiz kayma bölgesindeki artışla açıklanabilir. Ayrıca kanal açısındaki büyüme atık (hurda) malzeme oranını da arttırmaktadır.

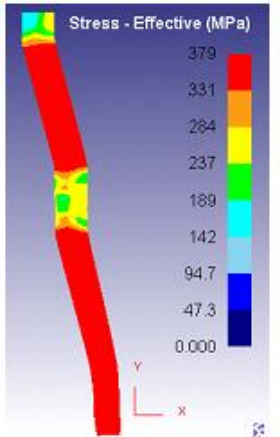

(a)

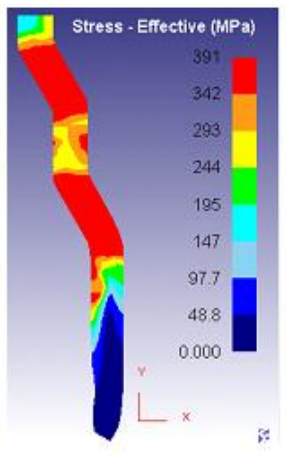

(b)

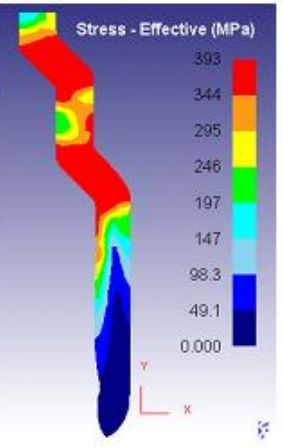

(c)

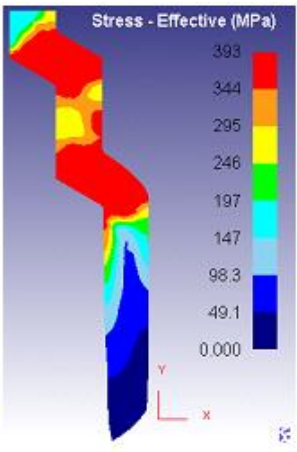

(d)

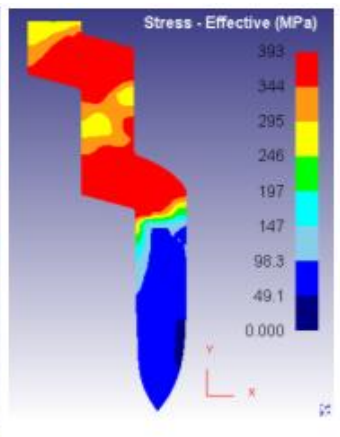

(e)

Şekil 5. Çift geçişli kalıplarda kanal açısının $(\varphi)$ gerilmeye etkisi. a) $\varphi=165^{\circ}$, b) $\varphi=150^{\circ}$, c) $\varphi=135^{\circ}$, d) $\varphi=120^{\circ}$, e) $\varphi=105^{\circ}$. 


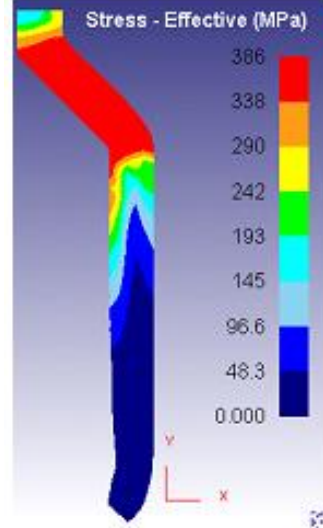

(a)

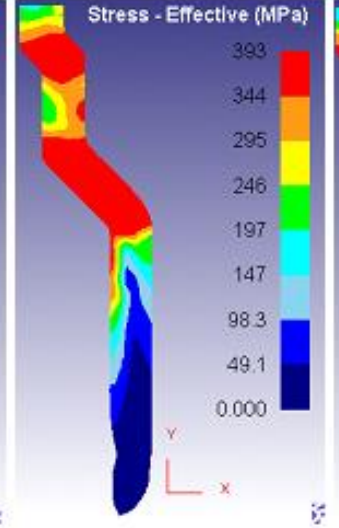

(b)

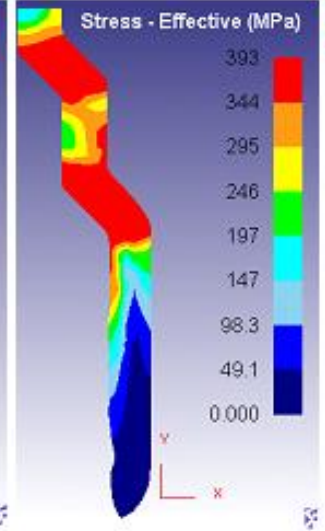

(c)

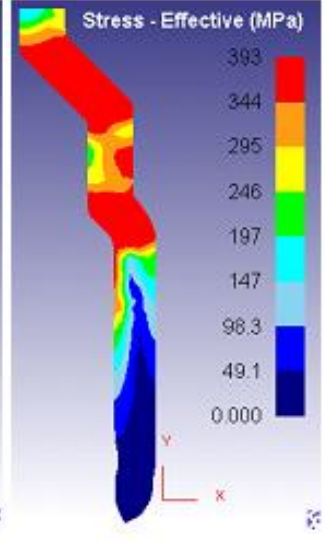

(d)

Şekil 6. Çift geçişli kalıplarda kesit genişlemesi oranı, $R_{A} / R_{T}$ 'nin gerilmeye etkisi. a) 0 (Tek geçiş), b) 0.25 , c) 0.50, d) 0.75 .

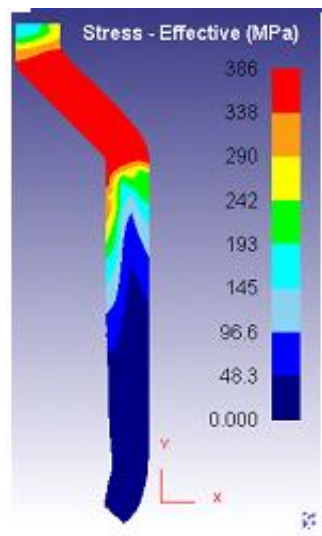

(a)

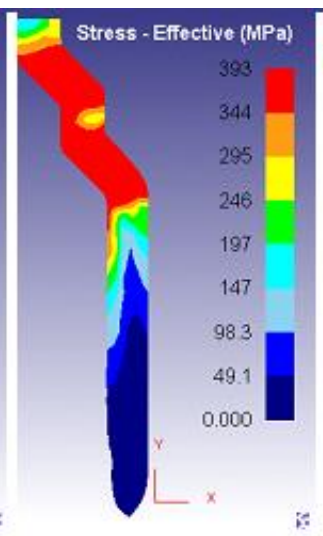

(b)

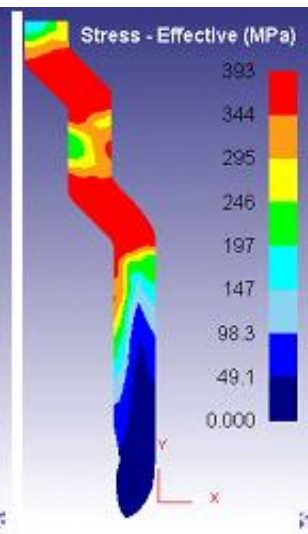

(c)

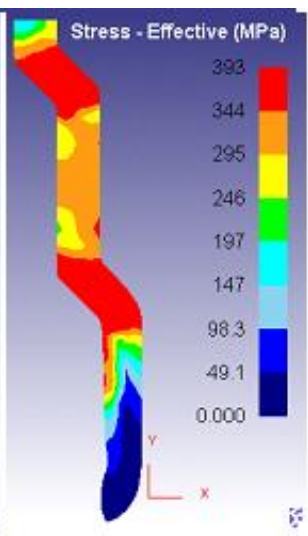

(d)

Şekil 7. Çift geçişli kalıplarda $\mathrm{L} / \mathrm{d}_{\mathrm{i}}$ 'nin gerilmeye etkisi. a) 0 (Tek geçiş), b) 0.125 , c) 0.25 , d) 0.5 .

\section{2. Şekillendirme kuvveti}

Yapılan analizler sonucu hem tek geçişli kalıplarda hem de çift geçişli kalıplarda kanal açısının şekillendirme kuvvetine olan etkileri Şekil 8 ve Şekil 9'da görülmektedir. Her iki şekilde de en düşük şekillendirme kuvveti $\varphi=165^{\circ}$ açıya sahip kalıpta, en yüksek kuvvet ise $\varphi=105^{\circ}$ elde edilmiştir. Kanal açısı ile şekillendirme kuvveti arasında ters bir ilişki vardır. Kanal açısı arttıkça şekillendirme kuvveti de düşmektedir. Kanal açısındaki düşüş malzeme akışını zorlaştırmakta ve daha yüksek şekillendirme kuvvetlerine ihtiyaç duyulmaktadır. Çift geçişli kalıplarda şekillendirme kuvvetinde önemli bir dalgalanmanın olduğu açık bir şekilde görülmektedir. Bu da çift geçişli kalıplarda malzeme akışında zorlukların olduğunu göstermektedir. Tek geçişli kalıplarda en yüksek şekillendirme kuvveti $\varphi=105^{\circ}$ 'de $126 \mathrm{kN}$ iken en düşük şekillendirme kuvveti $\varphi=165^{\circ}$ 'de $50.15 \mathrm{kN}$ 'dır. Çift geçişi kalıplarda ise en yüksek şekillendirme kuvveti $\varphi=105^{\circ}$ 'de $194 \mathrm{kN}$ iken en düşük şekillendirme kuvveti $\varphi=165^{\circ}$ 'de $53.11 \mathrm{kN}$ 'dır. Yine tek geçişli kalıplarda iki pik bölgesi varken, çift geçişli kalıplarda üç pik bölgesi vardır. 


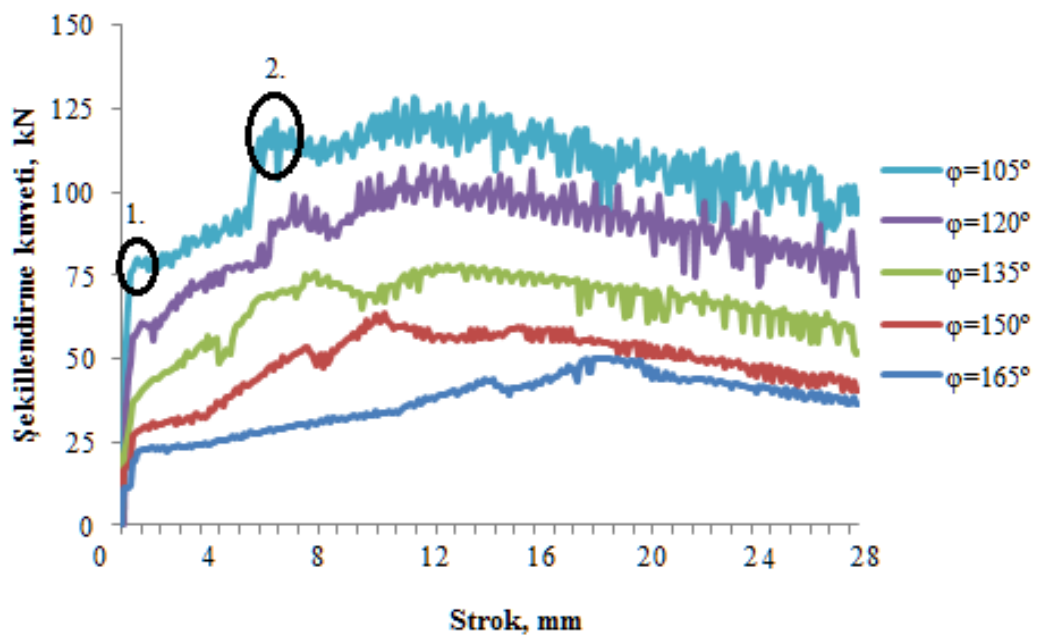

Şekil 8. Tek geçişli kalıplarda kanal açısının $(\varphi)$ şekillendirme kuvvetine etkisi.

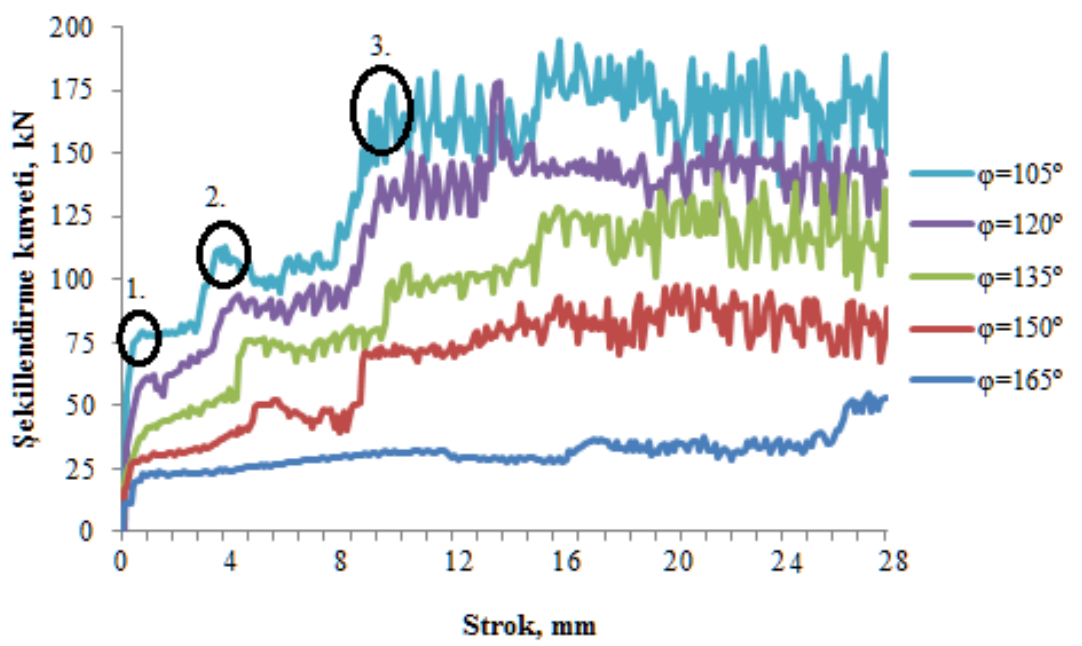

Şekil 9. Çift geçişli kalıplarda kanal açısının $(\varphi)$ şekillendirme kuvvetine etkisi.

\subsection{Efektif plastik şekil değişimi}

Plastik şekil değişiminin hem sertlik dağılımı hem de iç mikroyapı homojenliği üzerine önemli bir etkisi vardır [11]. Plastik şekil değişimindeki artış daha ince taneli ve mukavemetli malzemeler elde edilmesini sağlamaktadır. Şekil 10'de tek geçişli kalıplar, Şekil 11'de ise çift geçişli kalıplarla yapılan analizler sonucu elde edilen efektif plastik şekil değişimleri verilmiştir. Şekiller incelendiğinde kanal açısının artması ile deformasyon homojenliğinin arttığı görülmektedir [11, 27]. Ancak kanal açısındaki artışa bağlı olarak plastik şekil değişiminin düştüğü görülmektedir. Başka bir ifade ile kanal açısındaki düşüş malzeme akışını zorlaştırmakta bu da daha yüksek bir plastik şekil değişimi elde edilmesini sağlamaktadır. Tek geçişli kalıplar ile şekillendirme sırasında elde edilen en büyük efektif plastik şekil değişimi sırası ile $\varphi=165^{\circ}$ de $0.768, \varphi=150^{\circ}$ de 1.08 , $\varphi=135^{\circ}$ 'de $1.45, \varphi=120^{\circ}$ 'de 2.06 ve $\varphi=105^{\circ}$ 'de ise 3.92 iken çift geçişli kalıplar için ise sırası ile $\varphi=165^{\circ}$ 'de $0.977, \varphi=150^{\circ}$ 'de $1.81, \varphi=135^{\circ}$ de $2.93, \varphi=120^{\circ}$ 'de 4.02 ve $\varphi=105^{\circ}$ 'de ise $5.33^{\prime}$ 'dür. Şekil 12 ve Şekil 13 'de, tek ve çift geçişli kalıplarla şekillendirilen boruların efektif plastik şekil değişiminin teorik ve sonlu elemanlar analizi sonuçlarının karşılaştırması verilmiştir. Şekil 14'de ise çift geçişli kalıplarla şekillendirilen boruların efektif plastik şekil değişiminin bölgesel değişimi verilmiştir. Şekil 12 ve Şekil 13 incelendiğinde en yüksek şekil değişimlerinin boru iç yüzeyinde elde edildiği görülmektedir. Teorik hesaplamalar Eş. 2'deki denklem kullanılarak yapılmıştır. Teorik hesaplamalarda malzeme davranışı, sürtünme vb. etkenlerin hesaba katılmamasından dolayı tam bir uyumun olmadığı görülmektedir. Şekil 14 incelendiğinde tüm kanal açıları için 
en düşük efektif şekil değişiminin I. bölgede ve en yüksek efektif şekil değişiminin ise IV. bölgede olduğu görülmektedir.

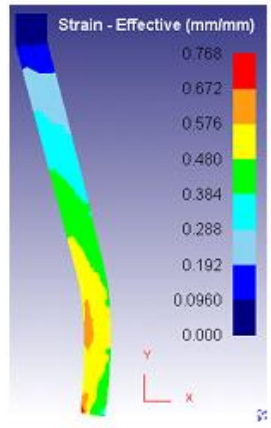

(a)

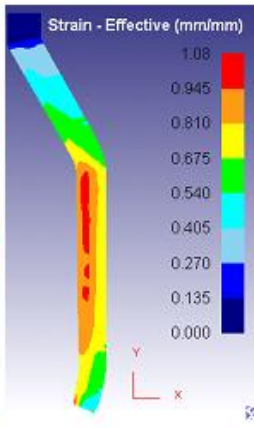

(b)

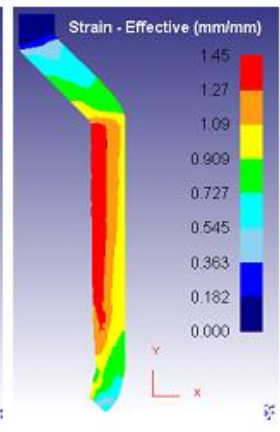

(c)

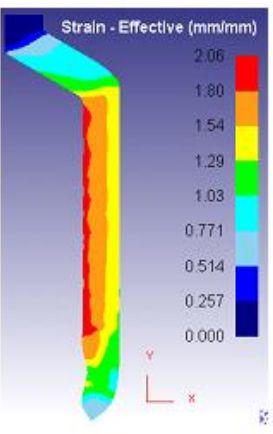

(d)

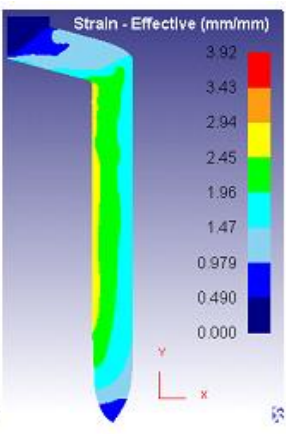

(e)

Şekil 10. Tek geçişli kalıplar için kanal açısının $(\varphi)$ efektif şekil değişimine etkisi. a) $\varphi=165^{\circ}$, b) $\varphi=150^{\circ}$, c) $\varphi$ $=135^{\circ}$, d) $\varphi=120^{\circ}$, e) $\varphi=105^{\circ}$.

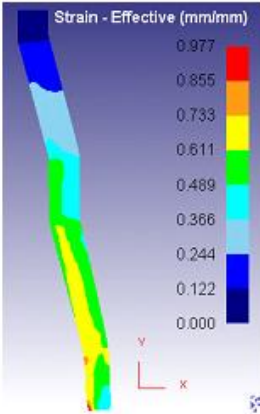

(a)

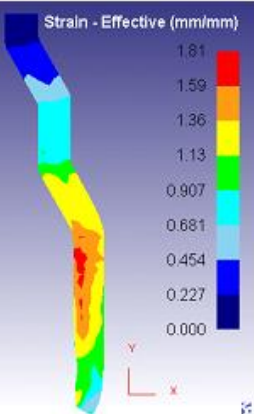

(b)

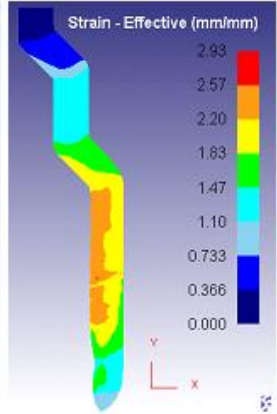

(c)

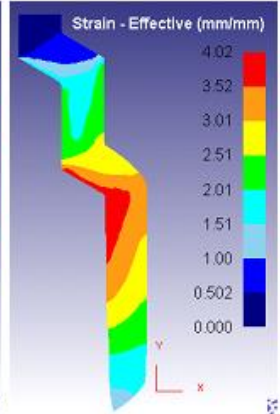

(d)

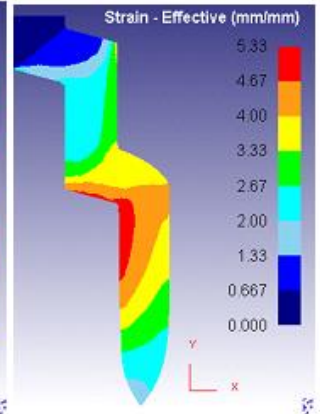

(e)

Şekil 11. Çift geçişli kalıplar için kanal açısının $(\varphi)$ efektif şekil değişimine etkisi. a) $\varphi=165^{\circ}$, b) $\varphi=150^{\circ}$, c) $\varphi$ $=135^{\circ}$, d) $\varphi=120^{\circ}$, e) $\varphi=105^{\circ}$.

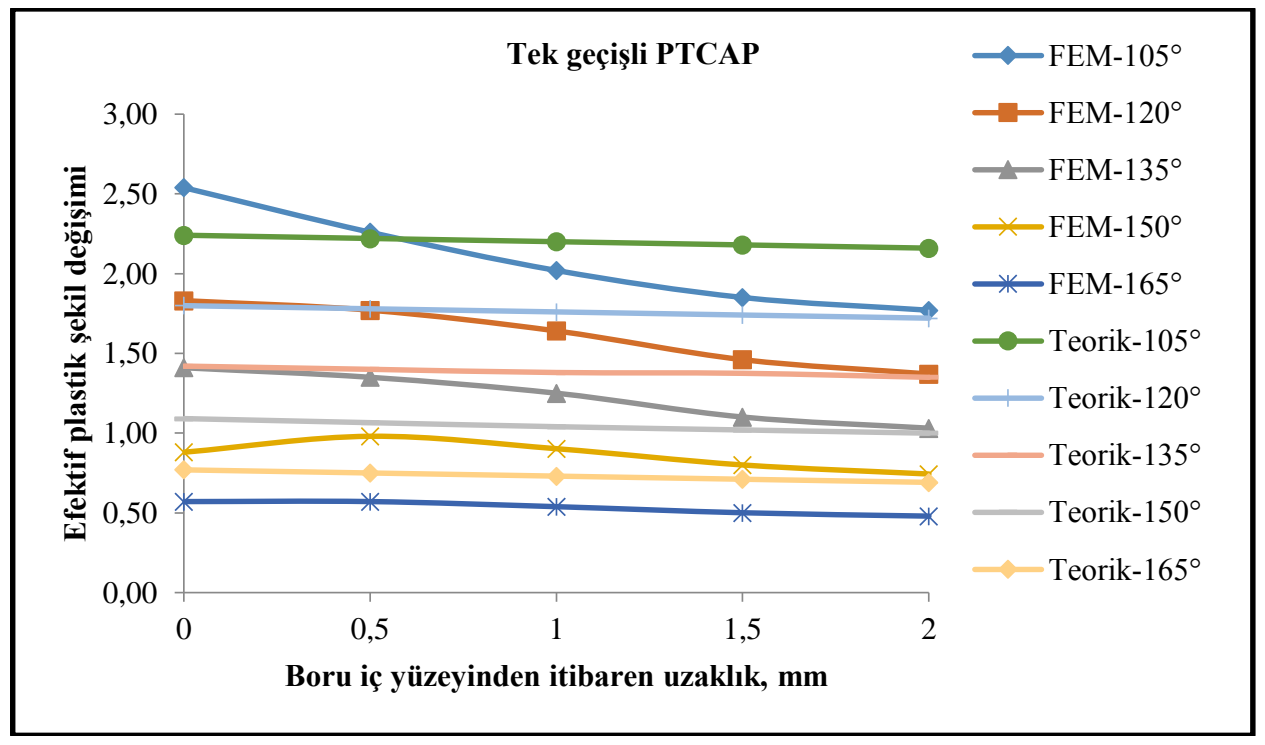

Şekil 12. Tek geçişli kalıplarla şekillendirilen boruların efektif plastik şekil değişiminin teorik ve sonlu elemanlar analizi sonuçlarının karşılaştırılması. 


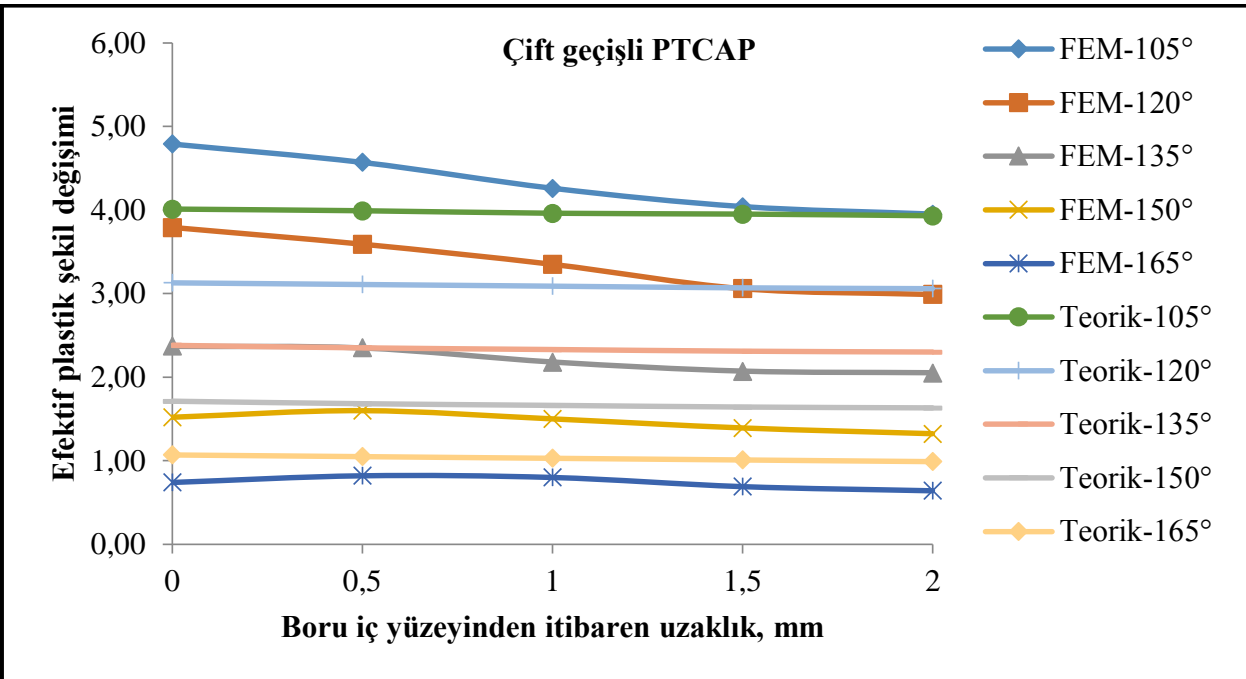

Şekil 13. Çift geçişli kalıplarla şekillendirilen boruların efektif plastik şekil değişiminin teorik ve sonlu elemanlar analizi sonuçlarının karşılaştırılması.

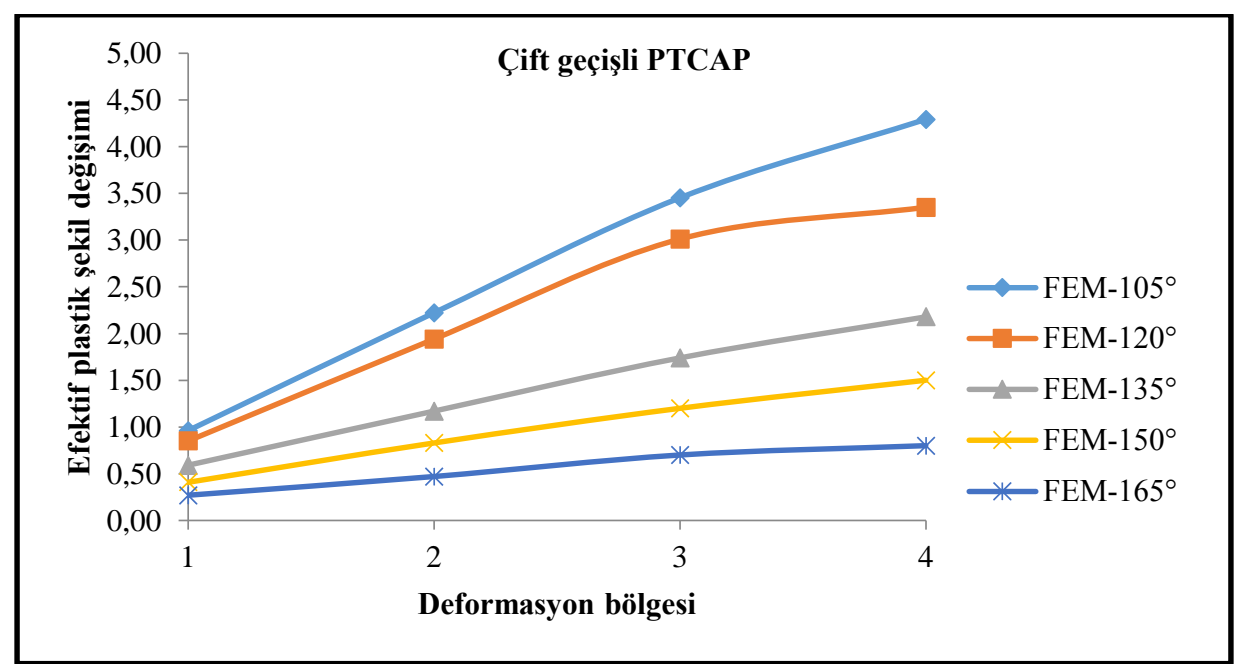

Şekil 14. Çift geçişli kalıplarla şekillendirilen boruların şekillendirme bölgelerindeki efektif plastik şekil değişimi.

Kesit genișlemesi oranı, $\mathrm{R}_{\mathrm{A}} / \mathrm{R}_{\mathrm{T}}$ 'nin şekillendirme esnasında malzemede oluşan efektif birim șekil değişimine etkisi Şekil 15 'de görülmektedir. $\mathrm{R}_{\mathrm{A}} / \mathrm{R}_{\mathrm{T}}=0$ iken tek kademeli bir geçiş olduğundan dolayı şekil değişimi en düşük çıkmıştır. Oran arttıkça birinci geçiş bölgesinin boyu artmakta ikinci geçiş bölgesinin boyu ise azalmaktadır. Birinci geçiş bölgesinin boyu arttıkça şekil değişimi düşmekte, ikinci geçiş bölgesinin boyu kısaldıkça da şekil değișimi artmaktadır. 


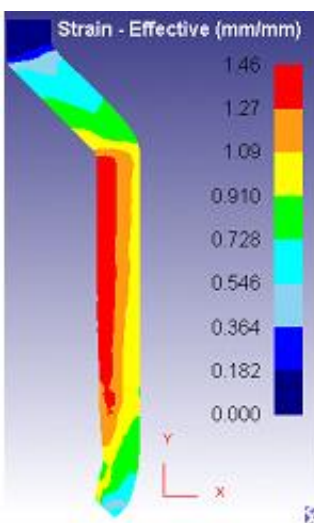

(a)

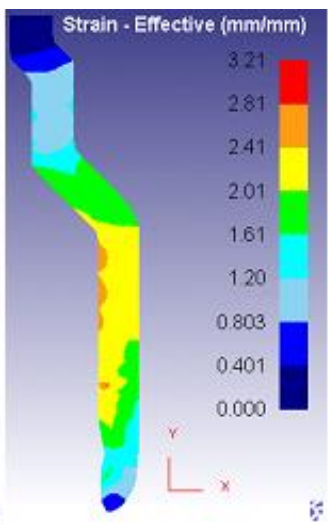

(b)

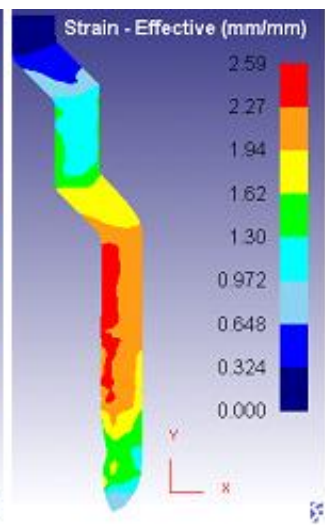

(c)

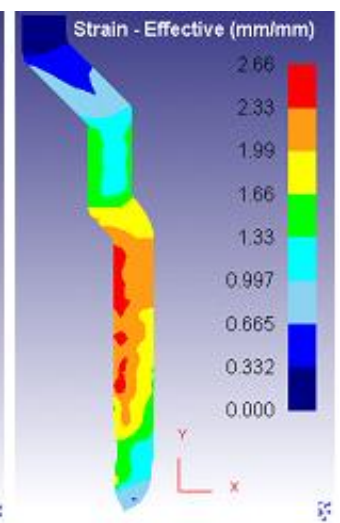

(d)

Şekil 15. $R_{\mathbb{A}} / R_{T}$ 'nin efektif şekil değişimine etkisi a) 0 (Tek geçiş), b) 0.25 , c) 0.50 , d) 0.75 .

Şekil 16 incelendiğinde boyutsuz uzunluk oranı, $\mathrm{L} / \mathrm{d}_{\mathrm{i}}=0 \mathrm{iken}$ tek bir geçiş bölgesi olduğu için malzeme akış esnasında bir engelle karşılaşmamakta bu da şekil değişiminin düşük çıkmasına neden olmaktadır. En büyük şekil değişimi $\mathrm{L} / \mathrm{d}_{\mathrm{i}}=0.125$ 'de elde edilmiştir. $\mathrm{Bu}$ durum birinci geçiş bölgesinin ardından $\mathrm{L}$ mesafesinin kısa olması sonucu ikinci geçiş bölgesine girilmesi ile gerilme değerindeki artışa paralel olarak daha yüksek şekil değişiminin oluşmasına neden olmuştur. L mesafesi arttıkça bu bölgede oluşan deformasyon, süreksizliğin azalması ile düşmekte bu da birim şekil değişimini azaltmaktadır.

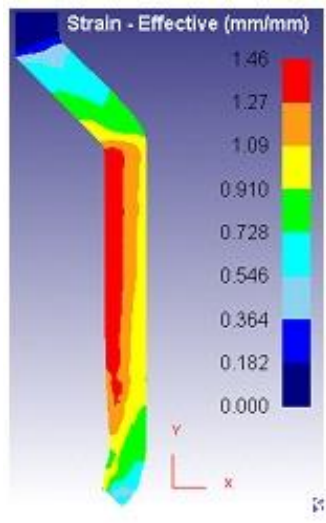

(a)

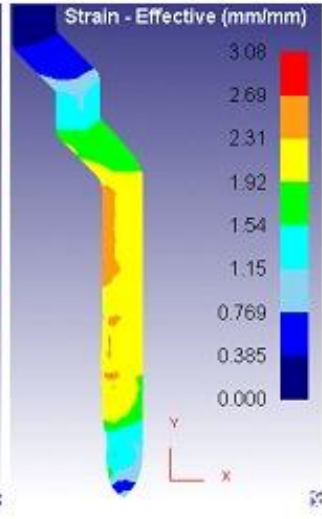

(b)

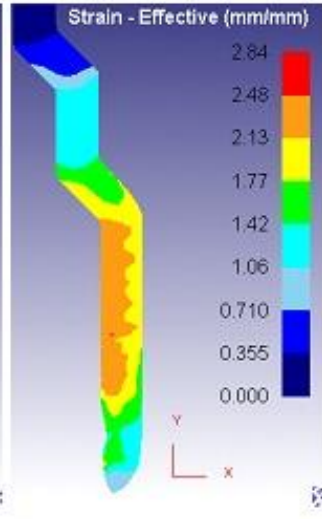

(c)

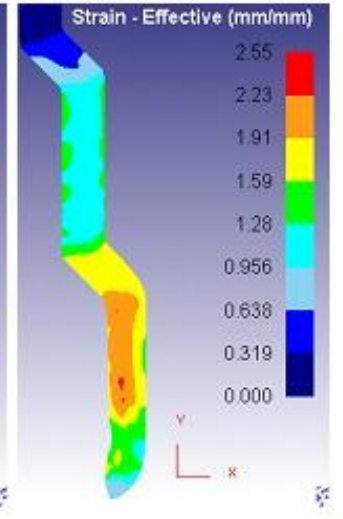

(d)

Şekil 16. $\mathrm{L} / \mathrm{d}_{\mathrm{i}}$ 'nin efektif şekil değişimine etkisi a) 0 (Tek geçiş), b) 0.125 , c) 0.25 , d) 0.5 .

\subsection{Optimizasyon deneyi}

En yüksek plastik deformasyon, Şekil 11'de $\varphi=105^{\circ}$, Şekil $15^{\prime}$ 'de $R_{A} / R_{T}=0.25$, Şekil $16^{\prime}$ 'da ise $L / d_{i}=0.125$ şartlarında elde edilmiştir. APD yönteminin amaçlarından biri de homojen ve hasarsız nano/ultra ince yapılı malzemeler elde etmektir. Bu da ancak daha yüksek deformasyon ile başarılabilir. Bu durum yeniden optimize edilerek bir kalıp tasarlanmıştır. Tasarlanan bu kalıp ile yapılan analizler sonucunda elde edilen birim şekil değişimi Şekil 17'de, şekillendirme kuvveti ise Şekil 18'de verilmiştir. Görüleceği üzere şekillendirme esnasında oluşan en büyük efektif şekil değişimi 7.53 olarak elde edilmiştir. En yüksek şekillendirme kuvveti ise $195 \mathrm{kN}$ olarak ölçülmüştür. 


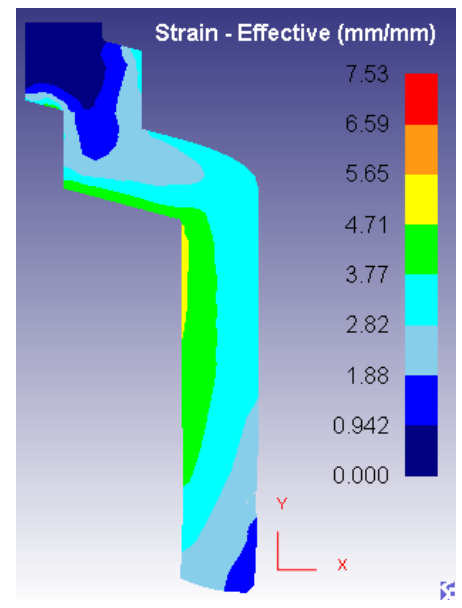

Şekil 17. Optimizasyon deneyi sonucu elde edilen birim şekil değişimi ( $\left.\varphi=105^{\circ}, R_{A} / R_{T}=0.25, L / d_{i}=0.125\right)$.

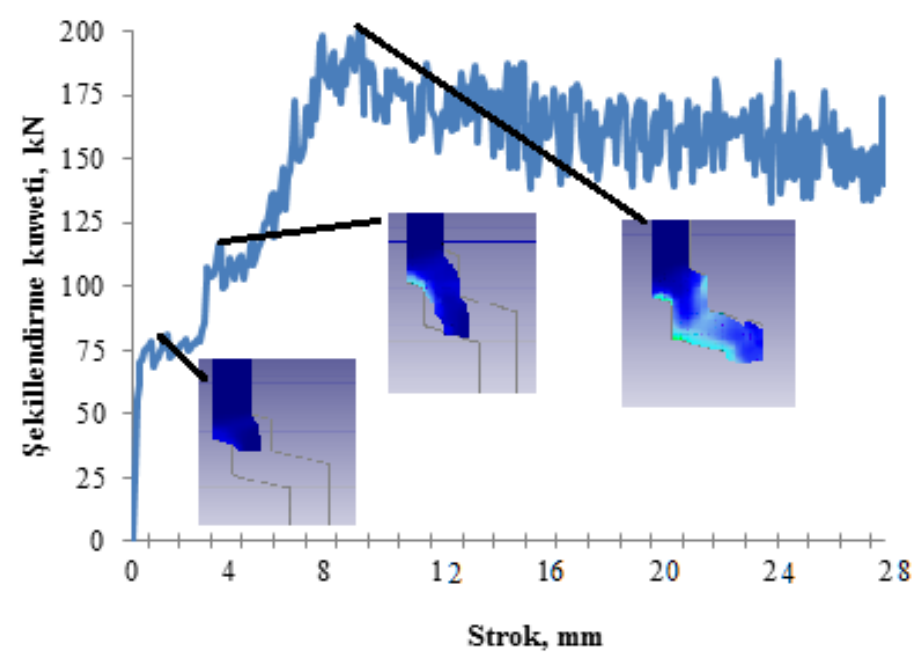

Şekil 18. Optimizasyon deneyi sonucu elde edilen şekillendirme kuvveti $\left(\varphi=105^{\circ}, R_{A} / R_{T}=0.25, L / d_{i}=0.125\right)$.

\section{Sonuçlar}

Bu çalışmada, boruların aşırı plastik deformasyonunda kullanılan yöntemlerden biri olan paralel tüp kanal açısal presleme (PTCAP) yönteminden farklı olarak çift geçişli paralel tüp kanal açısal presleme (DP-PTCAP) yöntemi ile AA6061 malzemenin sonlu elemanlar yöntemiyle analizi gerçekleştirilmiştir. Çalışma neticesinde aşağıdaki sonuçlar elde edilmiştir.

1. Kanal açısı arttıkça hem şekillendirme kuvveti hem de gerilme azalmıştır.

2. Kanal açısı arttıkça birim şekil değişimi azalmışıır.

3. En büyük şekil değişimi değeri $\varphi=105^{\circ} \mathrm{kanal}$ açında elde edilmiştir.

4. $L / d_{i}$ oranı arttıkça birim şekil değişimi düş̧ektedir.

5. $\mathrm{R}_{\mathrm{A}} / \mathrm{R}_{\mathrm{T}}$ oranı hem birim şekil değişimini hem gerilmeyi hem de şekillendirme kuvvetini önemli derecede etkilemiştir.

6. DP-PTCAP (Çift geçiş) işlemi sonucunda PTCAP (Tek geçiş) işlemine göre daha yüksek birim şekil değişimi elde edilmektedir. Her iki yöntemde de en yüksek şekil değişimi $\varphi=105^{\circ}$ açılı kalıpta elde edilmiştir. Ancak PTCAP işleminde 3.92 iken DP-PTCAP işleminde 5.33'dür. Artış \%35.97'dir.

7. En büyük şekil değişimi ve gerilme değerleri şekillendirilen parçanın iç yüzeyinde oluşmuştur.

8. Optimizasyon deneyinde şekillendirme esnasında ulaşılan en yüksek plastik şekil değişimi 7.53 olarak ölçülmüştür.

Aşırı plastik deformasyon işleminde önemli olan şekillendirme sonrası malzemede oluşan gerilme, birim şekil değişimi ve iç mikro yapının homojen dağılım göstermesi ve en yüksek şekil değişimini sağlayacak 
deformasyon şartlarını sağlamaktır. Şekil değişimindeki artış daha ince taneli ve daha yüksek mukavemetli malzeme elde edilmesinde önemli bir rol oynamaktadır.

\section{Kaynaklar}

[1] Nazari F, Honarpisheh M. Analytical model to estimate force of constrained groove pressing process. J Manuf Process 2018; 32: 11-19.

[2] Głuchowski W, Stobrawa J, Rdzawski Z, Malec W. Ultrafine grained copper alloys processed by continuous repetitive corrugation and straightening method. Mater Sci Forum 2011; 674: 177-188.

[3] Solhjoei N, Varposhty AR, Mokhtarian H, Manian A. A Comparative Study To Evaluate the Efficiency of Rcs and Cgp Processes. Indian JSciRes 2014; 1: 563-572.

[4] Shahmirzaloo A, Faraji G, Safari M, Mohammadinejad S. Interface sheet-constrained groove pressing as a modified severe plastic deformation process. Mater Sci Technol (United Kingdom) 2018; 34: 1669-1678.

[5] Yadav PC, Sinhal A, Sahu S, et al. Microstructural Inhomogeneity in Constrained Groove Pressed Cu-Zn Alloy Sheet. J Mater Eng Perform 2016; 25: 2604-2614.

[6] Valiev RZ, Estrin Y, Horita Z, et al. Producing Bulk Ultrafine-Grained Materials by Severe Plastic Deformation: Ten Years Later. Jom 2016; 68: 1216-1226.

[7] Afifi MA, Wang YC, Pereira PHR, et al. Mechanical properties of an Al-Zn-Mg alloy processed by ECAP and heat treatments. J Alloys Compd 2018; 769: 631-639.

[8] Kaya H, Uçar M, Cengiz A, et al. Novel molding technique for ECAP process and effects on hardness of AA7075. Mechanika 2014; 20: 5-10.

[9] Raj KH, Sharma RS, Singh P, Dayal A. Study of friction stir processing (FSP) and High Pressure Torsion (HPT) and their effect on mechanical properties. Procedia Eng 2011; 10: 2904-2910.

[10] Saito Y, Tsuji N, Utsunomiya H, et a. Ultra-Fine Grained Bulk Aluminum Produced By Accumulative Roll-Bonding ( Arb ) Process. Acta Metall 1998; 39: 1221-1227.

[11] Faraji G, Mosavi Mashadi M, Abrinia K, Kim HS. Deformation behavior in the tubular channel angular pressing (TCAP) as a noble SPD method for cylindrical tubes. Appl Phys A Mater Sci Process 2012; 107: 819-827.

[12] Toth LS, Chen C, Pougis A, et al. High pressure tube twisting for producing ultra fine grained materials: A review. Mater Trans 2019; 60: 1177-1191.

[13] Faraji G, Babaei A, Mosavi Mashadi M, Abrinia K. Parallel tubular channel angular pressing (PTCAP) as a new severe plastic deformation method for cylindrical tubes. Mater Lett 2012; 77: 82-85.

[14] Wang JT, Li Z, Weng J, Langdon TG. Principles of severe plastic deformation using tube high-pressure shearing. Scr Mater 2012; 67: 810-813

[15] Jafarzadeh H, Abrinia K. Fabrication of ultra-fine grained aluminium tubes by RTES technique. Mater Charact 2012; 102: $1-8$

[16] Babaei A, Mosavi Mashadi M. Tubular pure copper grain refining by tube cyclic extrusion-compression (TCEC) as a severe plastic deformation technique. Prog Nat Sci Mater Int 2014; 24: 623-630.

[17] Babaei A, Mosavi Mashadi M, Jafarzadeh H. Tube cyclic expansion-extrusion (TCEE) as a novel severe plastic deformation method for cylindrical tubes. J Mater Sci 2014; 49: 3158-3165.

[18] Mohebbi MS, Akbarzadeh A. Accumulative spin-bonding (ASB) as a novel SPD process for fabrication of nanostructured tubes. Mater Sci Eng A 2010; 528: 180-188.

[19] Bagherpour E, Qods F, Ebrahimi R, Miyamoto H. Microstructure evolution of pure copper during a single pass of simple shear extrusion (SSE): Role of shear reversal. Mater Sci Eng A 2016; 666: 324-338.

[20] Faraji G, Mosavi Mashadi M, Bushroa AR, et al. TEM analysis and determination of dislocation densities in nanostructured copper tube produced via parallel tubular channel angular pressing process. Mater Sci Eng A 2013; 563: 193-198.

[21] Javidikia M, Hashemi R. Analysis and Simulation of Parallel Tubular Channel Angular Pressing of Al 5083 Tube. Trans Indian Inst Met 2017; 70: 2547-2553.

[22] Afrasiab M, Faraji G, Tavakkoli V, et al. The Effects of the Multi-pass Parallel Tubular Channel Angular Pressing on the Microstructure and Mechanical Properties of the Cu-Zn Tubes. Trans Indian Inst Met 2015; 68: 873-879.

[23] Jafarlou DM, Zalnezhad E, Hassan MA, et al. Severe plastic deformation of tubular AA 6061 via equal channel angular pressing. Mater Des 2016; 90: 1124-1135.

[24] Şahbaz M, Kaya H, Kentli A. A new severe plastic deformation method: thin-walled open channel angular pressing (TWO-CAP). Int J Adv Manuf Technol 2020; 106: 1487-1496.

[25] Şahbaz M, Kentli A, Kaya H. Performance of Novel TWO-CAP (Thin-Walled Open Channel Angular Pressing) Method on AA5083. Met Mater Int. 2020.

[26] Nagasekhar A V., Tick-Hon Y, Seow HP (2007) Deformation behavior and strain homogeneity in equal channel angular extrusion/pressing. J Mater Process Technol 2007; 192-193: 449-452.

[27] Lu SK, Liu HY, Yu L, et al. 3D FEM simulations for the homogeneity of plastic deformation in aluminum alloy HS6061-T6 during ECAP. Procedia Eng 2011; 12: 35-40. 